\title{
Synthesis of Copolymers of Decylmethacrylate with Decene-1 as a Viscosity Additive
}

\author{
Elkhan U. Isakov, Jeyhun Sh. Hamidova, Elnara I. Hasanova \\ Institute of Chemistry of Additives Named after Academician A. M. Guliyev, Azerbaijan National Academy of Science, \\ Baku City, Azerbaijan \\ Email:aki05@mail.ru
}

How to cite this paper: Isakov, E.U., Hamidova, J.Sh. and Hasanova, E.I. (2017) Synthesis of Copolymers of Decylmethacrylate with Decene-1 as a Viscosity Additive. Open Journal of Yangtze Gas and Oil, 2, 82-91.

https://doi.org/10.4236/ojogas.2017.22006

Received: January 11, 2017

Accepted: April 23, 2017

Published: April 26, 2017

Copyright () 2017 by authors and Scientific Research Publishing Inc. This work is licensed under the Creative Commons Attribution International License (CC BY 4.0).

http://creativecommons.org/licenses/by/4.0/

\begin{abstract}
The article was dedicated to the copolymerization reaction of decylmethacrylate with decene-1. The copolymerizaion was realized with the participation of the inisiator the radical mechanism-izooil acid dinitrilyne. The learning of the polymerizaion reaction of decylmethacrylate with decene- 1 shows that, it is possible to analyse the polymer connections having any molecular mass and content with the way of changing the monomers correlation and reaction temperature, that, it is possible to manage it knowing the regularities of the process. The effect of decylmethacrylate decene- 1 copolymers to the viscositytemperature properties has been learnt. As the result it has been showed that, using the joint polymers of decylmethacrylate-decene- 1 in the content of the limpid oils as the thickener additive, it is possible to get the base oils with good viscosity-temperature properties.
\end{abstract}

\section{Keywords}

Decylmethacrylate, Decene-1, Copolymerization, Viscosity-Temperature Properties, Thickener

\section{Introduction}

The used lubricating oils must be in high quality in order to ensure the longtime and reliable exploitation of the machine and mechanisms. The quality of the lubricating oils is determined by the quality of the additives used in their content. Among these additives the viscosity additives are very special. So, they are used in getting the oils having high viscosity-temperature properties and the high viscosity index. If the base oil used in the preparation of the lubricating compositions doesn't meet the requirement for its index price, then the lubricating composition isn't prepared on the basis of this oil. That's why firstly the viscosity-temperature properties of the oil must be improved. For this purpose, 
usually the viscosity additives are used. Because using the polymer combinations in little amount $(1 \%-2 \%)$ the aim in front of you is achieved, and the way is regarded as a proven and simple way as well.

Some vinyl monomers-polyisobutylene, polyalkymethacrylates, vinyl and etc. are used as viscosity additives [1] [2] [3]. Viscosity additives, relatively high polymers or copolymers of vinyl monomers $(\mathrm{M}=8000-12,000)$ are used in concentrations of up to $3 \%$, and economically very beneficial. However, during operation they are subject to degradation and viscosity oil thickened by them falls below the minimum speed, which leads to premature failure of machinery.

Synthetic components, a relatively low molecular weight oligomers of $\alpha$-olefins $(M=3000-5000)$ are used at a concentration of $20 \%-30 \%$, and very resistant to disruptive influences. However, the way to improve the viscosity- temperature properties of petroleum oils is not economically profitable.

Finally, the use of a synthetic oil composed of mineral oils. Another way to obtain high-index oil is used as a base oil of synthetic products. This way is forced, because, in some cases, petroleum oils, despite the presence of the most effective additives in them do not satisfy the increasing demands of modern technology. In such cases, semi-synthetic or partially synthetic oils are used for the development of lubricating compositions.

In our opinion, a more simple and cost-effective way to obtain oils with good viscosity-temperature characteristics is the use of viscosity additives that are highly resistant to the destructive influences, i.e. development of more advanced viscosity additives.

Taking into account the known superiorities of the viscosity additives with polyalkylmethacrylate type, the investigations in the direction of getting the viscosity additives with polyalkylmethacrylate type chemically modified on a world scale are carried out. So, these additives are gained on simple technology, are simply modified chemically and are superior to other viscosity additives for the feature of improving the viscosity-temperature (specially the low temperature) of oils [4] [5] [6]. Only in polymer chain they are not stable against the destruction because of existence of four carbon atom [7] [8]. That's why to obtain a stable viscosity additives polyalkylmethacrylates are chemically modified [9], and the starting methacrylates are polymerized with stabilizing monomers [10]. One of the stabilizing monomers is alpha-olefins.

For the ability to improve the viscosity-temperature properties of oils, polyalkylmethacrylates have an advantage over other viscosity additives, but compared to polyolefins, they are more expensive and less resistant to destructive influences. So getting in one molecule both $\alpha$-olefins and connecting links of methacrylates, chemically modified polymeric compounds are of great interest.

Studying thermo destructive properties of the industrial oil I-12A with the addition of chemically modified olefins polyalkylmethacrylates and industrial type additives polyalkylmethacrylates (e.g., Viscoplex V-2-670) shows that viscosity decrease of the first is in the range of $3.0 \%-6.0 \%$, and for the second is $12.0 \%-17.8 \%$. This is connected with the formation of new chemical bonds in copolymers, and 
this connection is stronger than the bond straight chain polymers of $\mathrm{C}-\mathrm{C}$.

This article is also devoted to the preparation and the investigation of chemically modified polyalkylmetarylates with $\alpha$-olefins. As alkylmetarylate was taken decyl methacrylate, as $\alpha$-olefin-decene- 1 .

\section{Exsperiments}

\subsection{Copolymerization of Decylmetacrylate (DMAC) with Decene-1 (Dn-1)}

The copolymerization of decylmetacrylate with decene- 1 has been realized with the participation of isooil acid dinitrilin taken as inisiator on radical mechanism.

Decylmethacrylate has been gained in the result of the effect of metacrylate acid to decyl alcohol in laboratory condition. And decene-1 has been gained from ethylene oligomerization products. Both of monomers have been used freshly distilled form.

The effect of the temperature, reaction duration period, comonomer correlation, initiator density and solvent to the process have been learnt. The results have been given on the Table 1 .

As seen from the Table 1, if the reaction period is prolonged from 1 hour up to 3 hours, the yield of copolymer is raised from $60 \%$ up to $93 \%$. The next increase ( 4 hours) of the reaction period influences the yield of copolymer (95\%).

Changing the duration of the copolymerization reaction does not particularly affect the molecular mass of the copolymer-at this moment the copolymers with 13,000 - 14,500 interval molecular mass are gained. During the increase of inisiator amount from $0.1 \%$ up to $0.7 \%$, the yield of copolymer is increased from $15.4 \%$ up to $97.2 \%$, and the price of molecular mass is reduced from 10,000 up to

Table 1. Copolymerization of decylmetacrylate with decene-1.

\begin{tabular}{|c|c|c|c|c|c|c|}
\hline \multicolumn{4}{|c|}{ Copolymerization Condition } & \multirow{2}{*}{$\begin{array}{l}\text { Yield of Copolymer, } \\
\text { Mass \% }\end{array}$} & \multicolumn{2}{|c|}{ Copolymer Properties } \\
\hline $\begin{array}{l}\text { Monomers Ratio } \\
\text { DMAC:Dn-1 }\end{array}$ & $\begin{array}{l}\text { Amount of } \\
\text { Inisiator, \% }\end{array}$ & $\begin{array}{l}\text { Tempera-ture, } \\
{ }^{\circ} \mathrm{C}\end{array}$ & $\begin{array}{l}\text { Duration Period of the } \\
\text { Reaction, hour }\end{array}$ & & $\begin{array}{l}\text { Molecular } \\
\text { Mass }\end{array}$ & $\begin{array}{l}\text { The Ratio of the Mangas } \\
\text { DMAC:Dn-1 }\end{array}$ \\
\hline $90: 10$ & 0.5 & 70 & 1 & 60.1 & 13,000 & $12: 1$ \\
\hline $90: 10$ & 0.5 & 70 & 2 & 77.4 & 13,000 & 13:1 \\
\hline $90: 10$ & 0.5 & 70 & 3 & 93.3 & 14,000 & 11:1 \\
\hline $90: 10$ & 0.5 & 70 & 4 & 95.0 & 14,500 & 10:1 \\
\hline $90: 10$ & 0.1 & 70 & 3 & 15.4 & 10,000 & 19:1 \\
\hline $90: 10$ & 0.3 & 70 & 3 & 72.8 & 8500 & 10:1 \\
\hline $90: 10$ & 0.7 & 70 & 3 & 97.2 & 7000 & 10:1 \\
\hline $80: 20$ & 0.5 & 70 & 3 & 88.6 & 11,500 & $9: 1$ \\
\hline $70: 30$ & 0.5 & 70 & 3 & 75.7 & 9700 & $4: 1$ \\
\hline $60: 40$ & 0.5 & 70 & 3 & 60.1 & 7500 & $3: 1$ \\
\hline $90: 10$ & 0.5 & 60 & 3 & 80.2 & 13,000 & $2: 1$ \\
\hline $90: 10$ & 0.5 & 80 & 3 & 93.3 & 8700 & 11:1 \\
\hline
\end{tabular}


7000. So, during the radical polymerization the increase of the number of active centers causes the becoming shorter of the number of active polymer chains, increasing the yield and reducing lowers the price of molecular mass, and this is the conformity to natural laws accepted commonly.

The reducing of the yield of copolymers and their molecular mass is seen during the increase of the amount of decene- 1 in the first monomer mix: the yield is reduced from $93.3 \%$ up to $60.1 \%$, and the molecular mass from 13,000 up to 7500 (Figure 1). As is known, $\alpha$-olefins (decene-1) aren't polymerized on radical mechanism. Their including into joint polymerization leads to the break of polymer chain. At this moment, the common speed of the process is reduced, the gained joint polymer is characterized with more narrow molecular mass and regular structure. The content of the copolymer is more homogeneous as well.

Polymers have the high exploitation properties in the content of copolymer lubricating oil synthesized as the viscosity additive. Because of effect of the noted and in its turn it certifies once more the superiority of copolymerization as the stabilization method.

The learning of the dependence of the polymers yield and molecular mass from the temperature shows that, the increase of the reaction temperature from $60^{\circ} \mathrm{C}$ up to $80^{\circ} \mathrm{C}$ increase the copolymers yield from $80.2 \%$ up to $93.3 \%$. Only at this moment the price of the molecular mass reduces from 13,000 up to 8700 (Figure 2). It means that, the temperature increases the speed of the reactions causing the break of polymerization chain speed together with polymerization speed-that is, the increase of the temperature increases the speed of all reactions.

\subsection{Characteristics of the Copolymer of Decylmethacrylate- Decene-1}

The results of the copolymerization, as well as, the effect of the chemical nature of the solvent has been learnt. During the execution of the process in isooctan

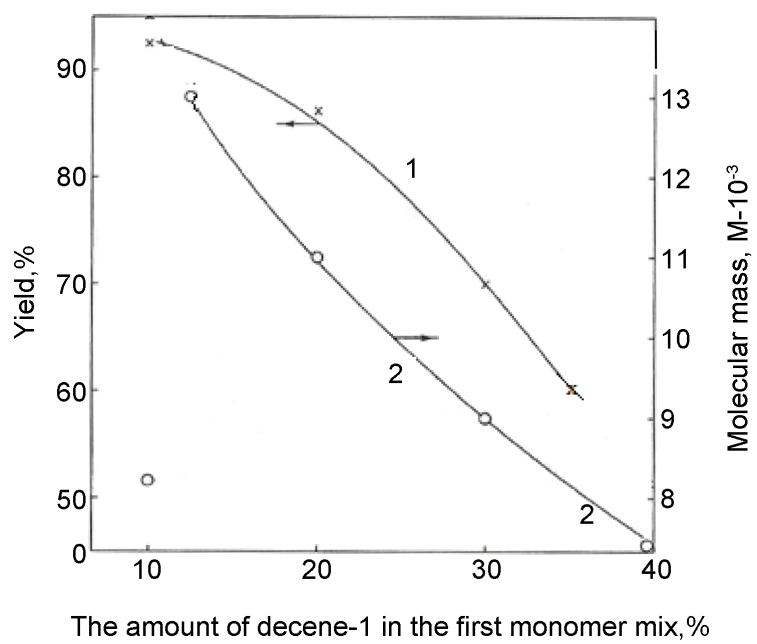

Figure 1. The dependence of the yield (1) and molecular mass (2) of the copolymer from the amount of decene- 1 in the first monomer mix. 


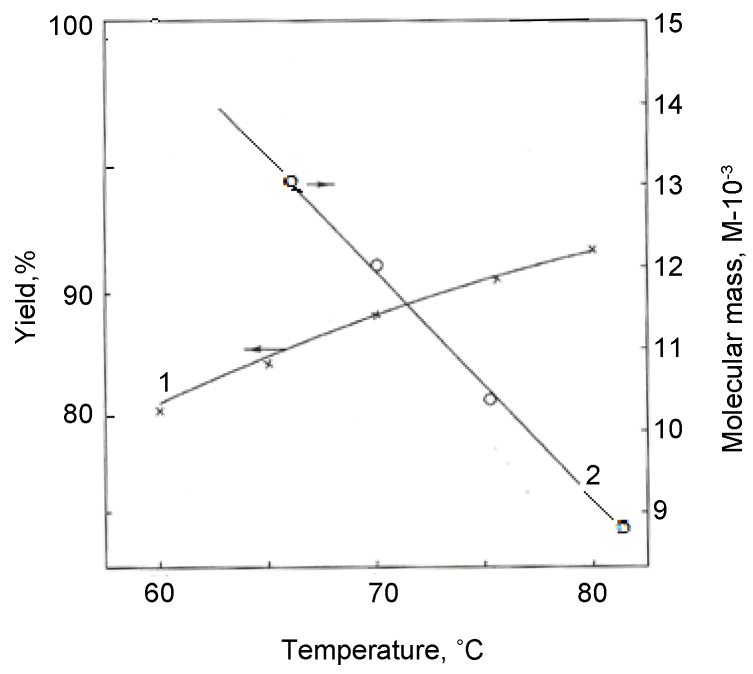

Figure 2. The dependence of the yield (1) and molecular mass (2) of the copolymer from the temperature.

atmosphere (monomers mix:isooctane $=1: 1$ ) it has been determined that, at the time the yield isn't changed, the price of the molecular mass is reduced from 9500 up to 6500. As is known, alyphatic hydrocarbons don't participate in the transfer of the polymer chain. So, the reducing of the molecular mass of copolymer is connected with the reducing of the density of the monomers mix-it reduces the probability of meeting of the monomer molecule with the active centers.

If using toluene as a solvent, the decrease of the molecular mass occurs more rapidly (it is reduced from 9500 to 4000) and toluene acts in two ways: diluting the mixture of monomers and involved in the transmission chain reaction.

Learning of the polymerizaion reaction of decylmethacrylate with decene-1 shows that, it is possible to synthesize the polymer combinations having any molecular mass and content with the way of changing of monomer colleration and reaction temperature, applying the solvent.

The spectral research was executed in order to certify the fact of existing of decene- 1 mangas in the content of the copolymer. According to IQ-spectr it is difficult to say the idea in this case, so, there is less difference between decene mangas and decylmethacrylate mangas.

Both manga are comprised of $-\mathrm{CH}_{2}-$ and $-\mathrm{CH}_{3}$ groups (compound ether group, -COOR isn't taken into account). The main difference is that, decene mangas has $>\mathrm{CH}-$ groups and this group gives absorption in $2700-2800 \mathrm{sm}^{-1}$ frequency area. In this absorption area the absorption area of $-\mathrm{CH}_{2}-$ groups are also seen and they film the absorption area of $>\mathrm{CH}-$ group.

According to PMR-spectr, it is difficult to give opinion about the existence of $>\mathrm{CH}-$ groups. The idea has been given according to the difference between the integral intensities of the signal in 3.75 m.p. chemical displacement characterizing $-\mathrm{CH}_{2}-$ groups by the carbonil group in PMR-spectr of copolymer together decene-1 with homopolymer.

The content of copolymer synthesized decylmethacrylate-decene- 1 has been 
appointed according to the percent of carbon. The results of this researches are given in the Table 2 .

As seen from the results of the executed research, it is not possible to increase the amount of decene- 1 mangas in the content of the joint polymer more than $27 \%$.

The speed constants of the copolymerization of monomer couples investigated have been appointed and these prices are given below:

for decylmethacrylate $r_{1}=1.33$.

for decene-1 $r_{2}=0$.

The sum $\left(p_{1} \cdot p_{2}=0\right)$ of the prices of speed constants of copolymerization is equal to zero. It means that, during the copolymerization of the mentioned monomer couples the real copolymers are gained which their monomer mangas are alternated in the proper rule. To be equal to zero of the copolymerization constant for decene-1 means that, decene-1 mangas aren't combined with each others, and this is characteristic for the radical polymeirzation of $\alpha$-olefins.

After realization of the researches, it is possible to give an idea about the learnt reaction:

Homopolymerization of decylmethacrylate:<smiles>C=C(C)C(=O)OCCCCCC(C)(C)CC(C)(C)C(=O)OCC</smiles>

This reaction is possible, that is, vinil monomers which are electroacseptor substitutes, are mainly polymerized on radical mechanism.

Homopolymerization of decene-1 on radical mechanism:

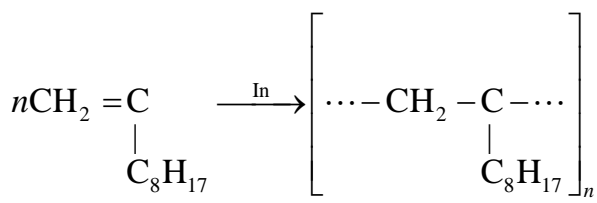

This reaction is not possible, so, $\alpha$-olefins are not polymerized on radical mechanism accoriding to the researches carried out by the authors $\left(r_{2}=0\right)$.

Polymerization of decylmethacrylate with decene-1:

Table 2. Content of copolymer decylmethacrylate-decene-1.

\begin{tabular}{cccccc}
\hline & \multirow{2}{*}{ DMAC:Dn-1 Ratio } & \multicolumn{4}{c}{ Element's Amount, \% } \\
\cline { 3 - 6 } & & \multicolumn{2}{c}{ Carbon } & \multicolumn{2}{c}{ Hydrogen } \\
\hline \multirow{2}{*}{ In First Mix } & In the Content of Copolymer & Calculated & Found & Calculated & Found \\
\hline & Polydecylmethacrylate & 74.30 & 73.90 & 11.51 & 11.43 \\
$90: 10$ & $91.1: 8.9$ & 75.44 & 74.60 & 12.17 & 11.89 \\
$80: 20$ & $87.6: 18.3$ & 76.58 & 75.97 & 12.23 & 11.91 \\
$70: 30$ & $76.9: 23.1$ & 77.78 & 77.13 & 12.28 & 12.03 \\
$60: 40$ & $72.4: 27.6$ & 78.80 & 78.21 & 12.31 & 12.16 \\
\hline
\end{tabular}




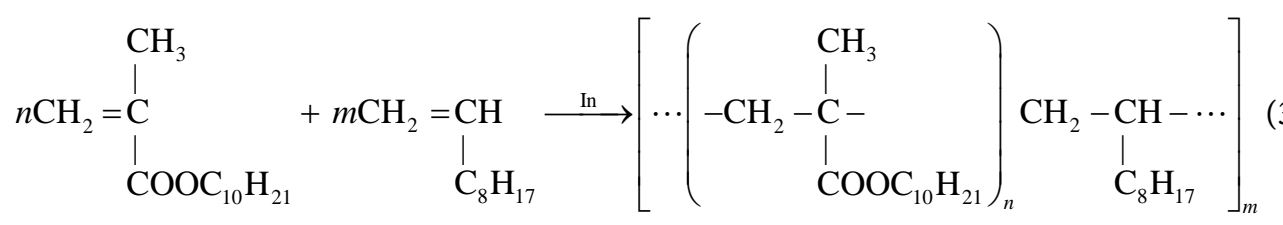

This reaction is desirable. It is expected that, decene- 1 mangas will be joined to the active centers of methacrylate and methacrylate to the active centers finishing with the decene (vinil monomers have the substitutes with different type). It is necessary to mention that, usually the active monomers form passive centers, and passive monomers form active centers. This fact shows itself in the reaction executed by the authors.

So, the expected reaction products are copolymers of decylmethacrylate with decene- 1 and partly the polydecylmethacrylate. According to the results of the carried researches, the following common formula (4) can be offered for copolymers synthesized.

$$
\left[\left(\begin{array}{c}
\mathrm{CH}_{3} \\
\cdots-\mathrm{CH}_{2}-\stackrel{\mathrm{C}-}{\mid} \\
\mathrm{COOC}_{10} \mathrm{H}_{21}
\end{array}\right)_{n} \quad \begin{array}{l}
\mathrm{CH}_{2}-\mathrm{CH} \\
\\
\mathrm{C}_{8} \mathrm{H}_{17}
\end{array}\right]_{m}
$$

where $n=2-9, m=6-12$.

\section{Results and Discussion}

\section{The Effect of Viscosity-Temperature Properties of Oils with the} Copolymers Decylmethacrylate-Decene-1

While researching the viscosity additives, as a rule, the effect of viscosity-temperature properties to their limpid petroleum oils are researched. That's why the search of the effect of viscosity-temperature properties of I-12A oil with decylmethacrylate-decene-1 copolymer to the researches was the beginning.

Table 3 (and on the Figure 3) show the results of the effect of the copoly-mer having 10,000 molecular mass and 10\% decene-1 mangas to viscosity-temperature properties of I-12A oil.

As seen from Table 3, the price of the condensed oil viscosity index increases

Table 3. The effect of the copolymers decylmethacrylate-decene-1 to the viscositytemperature properties of I-12A oil.

\begin{tabular}{ccc}
\hline Density of Copolymer, \% & Kinematic Viscosity in $100^{\circ} \mathrm{C}, \mathrm{mm}^{2} / \mathrm{s}$ & Viscosity Index \\
\hline 0 & 3.26 & 90 \\
0.5 & 3.96 & 119 \\
1 & 4.41 & 130 \\
3 & 5.78 & 146 \\
5 & 6.65 & 148 \\
7 & 8.26 & 150 \\
9 & 9.84 & 150 \\
\hline
\end{tabular}




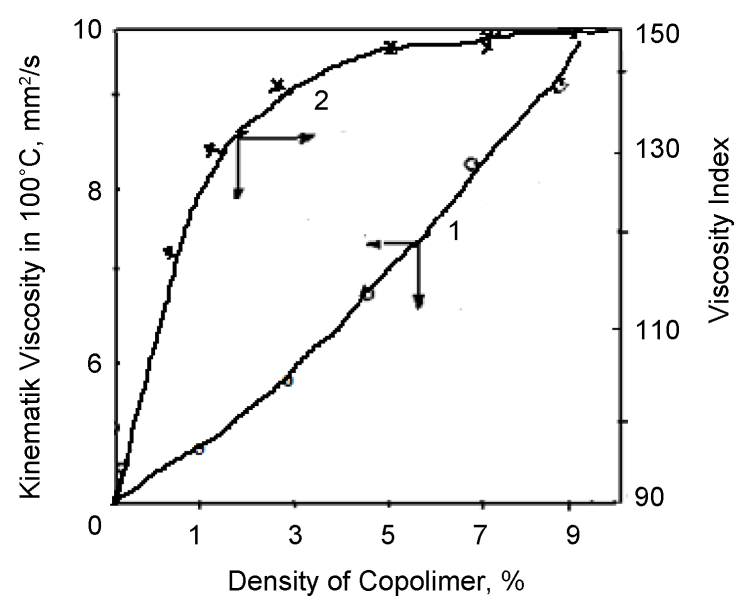

Figure 3. Viscosity-temperature properties of I-12A oil with copolimer.

from 90 up to 148 gained during the increasing $5 \%$ in the content of I- $12 \mathrm{~A}$ oil of the joint polymer density. So, its viscosity-temperature properties comes better.

The price of viscosity index characterizes the dependence of petroleum oil viscosity from the temperature. The concentration of polymer in the composition of the oil is less when the interaction between molecules is weak. Such molecules behave themselves independently and they are less dependant on temperature in their movements. As a result, the price of viscosity index of such oils is high.

Thermal destrcution of turbine oil "L" synthesized copolymer in oil solution has been learnt. Thermal destruction of the investigated samples was carried out by heating their $5 \%$ solution in the turbine oil at the temperature of $200^{\circ} \mathrm{C}$ within 12 hours.

During testing at intervals the reduction of viscosity (r.v.) is determined according to the following formula (5):

$$
\text { r.v. }=\frac{v_{u}-v_{k}}{v_{u}} \cdot 100 \%
$$

where $v_{u}$-Initial kinematic viscosity of solidified oil.

$v_{\kappa}$-The same after the test.

The results of the executed research have been generalized in the Table 4.

As seen from the Table 4, the increase of the amount of decene-mangas from $10 \%$ to $30 \%$ in the content of the copolymer in the same price of the molecular mass (8000) increases the stability against the thermical destruction of the condensed oil. The viscosity decrease of the oil from $7.7 \%$ up to $4.6 \%$ is reduced from the result of the destruction. The increasement of decene- 1 mangas in the content of the copolymer up to $40 \%$ doesn't increase the stability of the condensed oils.

When the price of molecular mass of the copolymer increases (with the content the ratio 80:20) from 8000 up to 13,000 , the decrease of viscosity of the condensed oil is increased from $5.9 \%$ up to $11.5 \%$ in the result of the thermical destruction. This can be explained by: it is known that, in the result of high 
Table 4. Thermical destruction of decylmethacrylate decene-1 joint polymers in oil solution.

\begin{tabular}{cccccc}
\hline $\begin{array}{c}\text { Mass of } \\
\text { copolymers, } \\
\text { Molecule }\end{array}$ & $\begin{array}{c}\text { Ratio of } \\
\text { copolymers' } \\
\text { DMAK:Dn- }\end{array}$ & \multicolumn{4}{c}{ Viscosity Decrease of oil solution, \% on the period (Hours) } \\
\cline { 3 - 6 } & $90: 10$ & 4.8 & 5.8 & 6.9 & 12 \\
\hline 8000 & $80: 10$ & 4.6 & 5.1 & 5.5 & 5.7 \\
8000 & $70: 30$ & 3.4 & 4.6 & 4.6 & 4.6 \\
8000 & $60: 40$ & 2.3 & 3.4 & 4.5 & 4.5 \\
8000 & $80: 20$ & 5.5 & 9.0 & 9.2 & 9.5 \\
10,000 & $80: 20$ & 9.5 & 10.5 & 11.5 & 11.5 \\
13,000 & & Polydecylmethacrylate & & \\
13,000 & - & 12.5 & 14.0 & 15.8 & 17.9 \\
\hline
\end{tabular}

temperature the heat movement of the moleculs increases. The heat movement of the molecules in the small prices of the molecular mass is relatively small and it not requires the energy. The greater the molecular mass, the more difficult the heat movement is. The energy needed for their movement is more than the energy of $\mathrm{C}-\mathrm{C}$ bond energy needed for theeir movement. As a result, this bond is broken, and the molecule is smashed to pieces. At this time the condensing ability of small molecular combinations are less than the condensing ability of the polymer, in the result the viscosity of the condensed oil viscosity is decreased and this is not a desirable case. Therefore, the molecular weight of the polymer to thicken the oils need to be chosen so that its destruction was minimal.

Attention to be paid to the dependence of the destruction of the oil solution of copolymer in time as the destruction happens in the first hour of the process. It means that, the polymers with high molecular mass and the chains with "weak" bond are destructed firstly because of the effect of the high temperature; while the process lasts, the content of the copolymer is stabilized, its molecular mass changes a little. An a result, the content of the condensed oil viscosity is changed because of temperature effect.

For comparison, the produced polyalkylmethacrylate (PMA "B") and condensed oil have been used.

As seen from the table in the same price $(13,000)$ the oils condensed with the copolymers are more stable than the polyalkylmethacrylates against the copolymers, and it certifes the authneticity of the method of synthesis of the stabile viscosity additives by the way of polymerization.

As can be seen the price of viscosity decrease depends on the molecular mass, and shows that the copolymer with 8000 molecular mass is more stable. Only with these copolymer the expense of the polymer for getting the condensed oil is better, and this is not profitable from economic point of view. That's why it is purposely to use the viscosity additive with 10,000 molecular mass and the joint polymers having $20 \%$ desene- 1 mangas in their content. 


\section{Conclusion}

So, using the decylmethacrylate-decene-1 copolymers in the content of the limpid oils is possible to gain the condensed base oils with different appointment high stable against the thermical destruction. But in any case, the price and the preparation of the chemical content of the molecular mass of the copolymer offered as the viscosity additive is determined depending on need arising from the exploitation qualities of the lubricating oils.

\section{References}

[1] Kaplan, S.Z. and Radzevenchuk, I.F. (1982) Viscousity Additives and Thickened Oils. L: Chemistry.

[2] Kuliyev, A.M. (1985) Chemistry and Technology of Additives to Oils and Fuels. L: Chemistry.

[3] Ahmedov, A.I., Farzaliyev, V.M. and Aliguliyev, R.M. (2000) Polimeric Additives and Oils. Elm, Baku.

[4] Yukich, A., Vidovich, E. and Yanovich, Z. (2007) Additives to Improve the Viscosity Index Oils. Chemistry and Technology of Fuels and Oils, 5, 23-27.

[5] Yanovich, Z., Yukich, A. and Vidovich, E. (2009) Triple Polymers of Maleic Anhydride and Long Chain Alkylmethacrylate as a Viscosity Additive. Chemistry and Technology of Fuels and Oils, 4, 33-37.

[6] Ahmedov, A.I. (2002) Condition of the Investigations of Synthesis of Viscosity Additives in the Country. Journal of Azerbaijan Oil Industry, 4, .37-39.

[7] Akhmedov, A.I. (2009) Some Principles of Synthesis of the Viscosity Additives. Azerbaijan Chemicai Journal, 1, 92-95.

[8] Akhmedov, A.I., Askerova, Kh.A., Isakov, E.U. and Gamidova, D.Sh. (2009) Synthesis of Copolymers of Bytylmethacrylate with Allylnaphtanate and a-Olefins as Viscous Additives to Lubricating Oils. Petro refining and Petro Chemistry, 5, 31-32.

[9] Akhmedov, A.I., Gamidova, D.Sh. and Isakov, E.U. (2014) Viscosity Additives Polyalkylmethacrylate-Type. LAP Lambert Academic Publishing, Germany.

[10] Farzaliyev, V.M., Akhmedov, A.I. and Hasanova, E.I. (2012) Synthesis of Copolymers of Decylmethacrylate with a-Allylphenol and Investigation of Them as Viscous Additives to Petroleum Oils. Russian Journal of Applied Chemistry, 85, 1717 1719 . 
Submit or recommend next manuscript to SCIRP and we will provide best service for you:

Accepting pre-submission inquiries through Email, Facebook, LinkedIn, Twitter, etc. A wide selection of journals (inclusive of 9 subjects, more than 200 journals)

Providing 24-hour high-quality service

User-friendly online submission system

Fair and swift peer-review system

Efficient typesetting and proofreading procedure

Display of the result of downloads and visits, as well as the number of cited articles Maximum dissemination of your research work

Submit your manuscript at: http://papersubmission.scirp.org/

Or contact ojogas@scirp.org 